\title{
A NOÇÃO DE AUTONOMIA E A DIMENSÃO DO VIRTUAL
}

\begin{abstract}
RESUMO. O artigo discute a relação entre a Biologia do Conhecimento de H. Maturana e F. Varela e a filosofia de H. Bergson. Os conceitos de autonomia e autopoiese propostos por Maturana e Varela no campo dos estudos da cognição são articulados com o conceito bergsoniano de virtual. Tais articulações são possibilitadas por afinidades entre os dois campos conceituais investigados. O conceito de subjetividade é articulado à dinâmica circular e paradoxal da autopoiese. É afirmado que esta dinâmica circular pode ser pensada a partir da lógica da criação em Bergson e que implica a distinção entre o atual e o virtual.
\end{abstract}

Palavras-chave: autonomia, autopoiese, virtual.

\section{THE RELATIONSHIP BETWEEN AUTONOMY AND VIRTUALITY}

\begin{abstract}
This paper presents connections established between Maturana and Varela's biology of knowledge and Bergson's philosophy. The concepts of autonomy and autopoiesis from Maturana and Varela's cognitive theory are articulated with Bergson's concept of virtuality. Such articulation is made possible due to the affinities of both conceptual fields. The concept of subjectivity is articulated with both the circular and paradoxical dynamic of autopoiesis and the concept of virtuality.
\end{abstract}

Key words: cognition, autonomy, autopoiesis, virtuality. ${ }^{1}$

O presente artigo trata de um problema surgido no domínio das teorias cognitivistas atuais, mais especificamente, no que se chama de biologia do conhecimento. Os trabalhos de Humberto Maturana e Francisco Varela aparecem, no início da década de 1970, como uma alternativa teórica no campo dos estudos da vida. Devemos entender que estes estudos em biologia não são assim definidos por se preocuparem essencialmente com a investigação das faculdades cognitivas. $\mathrm{O}$ que caracteriza essa biologia do conhecimento é antes o seu princípio norteador, a saber, que há uma identidade entre vida e cognição. A biologia é agora, por definição, um estudo dos fenômenos cognitivos com os quais se pode identificar o vivo. A nosso ver, esse problema faz eco a um outro: a produção da subjetividade. Trata-se do problema da relação de imanência - se assim podemos nos exprimir - entre viver, conhecer e fazer. Os teóricos da biologia do conhecimento, Maturana e Varela resumem essa questão através de uma dupla afirmação: o ato cognoscente confunde-se com a operação mesma de autocriação (autopoiese) que definiria a essência dos sistemas vivos; o conhecimento é criação, e não representação. Um deslocamento tão radical de perspectiva só tem par em certas concepções filosóficas como, por exemplo, a de Bergson, com a qual não deixa de ter muitos pontos em comum ${ }^{1}$. Não reduzir a vida ao vivo, mas mesmo assim mostrar no vivo a operação fundamental da vida - autocriação, autopoiese —, eis o que distingue a biologia do conhecimento de uma mera "ciência da cognição".

A vida passa ao primeiro plano, o que poderia caracterizar a empreitada de Varela e Maturana como um vitalismo imanente, poi justamente é no viver do ser vivo, e não em algum tipo de princípio

* Doutor em Filosofia pela Universidade Paris 8, Docente do Departamento de Psicologia da Universidade Federal Fluminense.

\# Doutor em Psicologia pela Fundação Getúlio Vargas-FGV, Docente do Departamento de Psicologia da Universidade Federal Fluminense.

1 Virgínia Kastrup (1995) chega a dizer que a ciência contemporânea, da qual fazem parte Maturana e Varela, e que se caracteriza pela mise en circuit da problemática do tempo como instância criadora, é, "neste sentido, efeito da filosofia bergsoniana" (p.92). 
transcendente, que se concentram os esforços para pensá-la como um processo de autocriação contínuo. É, então, necessário determinar em que sentido os teóricos da biologia do conhecimento, ao lançar mão da noção de autonomia, no sentido de autocriação e autopoiese, estão colocando um problema muito mais amplo do que o da natureza da cognição.

Como dizíamos, este problema concerne à natureza da nossa existência, e não só àquela de nossa sobrevivência, ou mesmo de nossas vidas, se se entende por "vida" algo ligado à conquista de status social, de desenvolvimento de carreira profissional, de direito civil, de bem-estar em família ou sociedade, ou seja, de tudo aquilo que se pode compreender pelas expressões "padrão de vida", "qualidade de vida" etc. Tudo isso se constitui em função - contra ou a favor - de nossos modos de vida, dos tipos de subjetividade nos quais nos configuramos, enfim, de nossa existência.

Em seu livro Autonomie et connaissance: essai sur le vivant (1989a), Varela define o que seria próprio dos sistemas naturais: sua capacidade de interagir consigo mesmos, autodeterminando-se. Daí a oposição aos sistemas de comando ou heterônomos cujo funcionamento é determinado extrinsecamente. Conforme este segundo modelo, definem-se os sistemas informacionais do tipo input/output que têm o seu comportamento orientado a partir de instruções externas. A hegemonia deste modelo de comando foi estabelecida, no campo da ciência cognitiva, a partir dos anos 1950, com o impacto causado pelas pesquisas computacionais. Os estudos da cognição ganharam um impulso especial quando as pesquisas em inteligência artificial pareceram atestar a fecundidade da hipótese acerca da identidade funcional homem/máquina. A cognição, qualquer que seja a sua base material (o cérebro ou o hardware do computador) passa a se definir como um processo simbólico de tratamento de informação, isto é, o sistema conhece na medida em que é informado e processa símbolos a que correspondem estados de coisas do mundo. Enquanto o modelo do comando enfatiza a noção de informação como instrução e representação, fazendo da identidade do sistema um fato informacional, o modelo da autonomia produz um deslocamento do eixo de análise: desloca o problema da instrução para aquele da construção; desloca o problema da representação para aquele da maneira como o comportamento adequado reflete a viabilidade do funcionamento do sistema (Varela, 1980/1989a, p. 9). Conhecer não é adequar-se a uma realidade do meio, tampouco é tão-simplesmente acionar estruturas cognitivas preexistentes no sistema. A relação entre cognição e criação se impõe agora como saída dos limites estreitos impostos pelo modelo do comando. A vida é criação e conhecer é um ato de poiesis. Daí a relação entre estes termos — viver, conhecer e fazer — , o que leva a uma redefinição também do objeto da biologia. O vivo é, portanto, o domínio da autonomia por excelência, já que sua existência se define e constrói a partir de um ato pragmático — ato a um só tempo criador e cognitivo daquele que vive/conhece e do mundo vivido/conhecido.

Consideremos mais detidamente o sentido que Varela dá à noção de autonomia. Palavra composta de "auto", que quer dizer o próprio, o si-mesmo, e de "nomos", que quer dizer lei ou norma, autonomia seria, então, dar-se a si mesmo suas próprias regras, e se oporia a heteronomia, que indicaria o estado daquele, ou daquilo, que é regrado, determinado por outro. Até aí, concordamos ; mas queremos colocar a seguinte questão: o ato mesmo de dar a lei ou a regra não supõe, para ser compreendido, algum tipo de mediação, ou talvez de distância entre a lei dada e o modo de ser que se conforma a ela? O que viria a ser, então, a autonomia, se todo ato de legislar supusesse uma tal mediação? Aquele que se diz autônomo verse-ia de imediato dividido em dois, partido em dois pedaços: um onde se instalaria toda a espontaneidade que a atividade de legislar implica, e outro, onde se localizaria toda a docilidade, para não dizer passividade, que implica a atividade de se conformar à lei dada. E ainda, seria preciso supor uma forma pela qual a lei dada se aplica necessariamente àquilo que ela pretende legislar, ou, em outros termos, supor uma forma do legislável em geral, capaz de reunir as duas partes inconciliáveis: a que dá a lei e que, portanto, é pura determinação, e a que recebe a lei e que, logo, é puramente indeterminado ${ }^{2}$.

Pensando desta forma, afirmamos que a autonomia, por um efeito de retroação sobre si mesma, engoliria a heteronomia e esta última, no final das contas, passaria a ser o princípio da primeira, constituindo-se como a sua possibilidade. Não nos parece que seja este o sentido que Varela daria à sua noção de autonomia. Nosso desafio, então, é tentar pensar a autonomia como primeira em relação à heteronomia (ou aonomia, como algumas vezes aparece nos textos desse autor), de tal modo que o ato de dar a lei e o ato de se conformar a ela fossem um só

Estamos aqui utilizando a forma do argumento deleuziano quando, em Diferença e Repetição (1988/1968, p. 150151), compara o cogito cartesiano e o cogito kantiano. Não queremos dizer com isto que o argumento de Deleuze nesta passagem trate do tema da autonomia, mas apenas que sua forma é utilizável na nossa discussão. 
ato em via de se fazer. Para tanto, é preciso que se pense a autonomia não apenas como o ato de se determinar a si mesmo, no sentido fraco, mas como o ato de criar-se a si mesmo, no sentido forte. A noção de criação passa ao primeiro plano, enquanto a noção de lei ou determinação adquire um sentido novo, já que aparece como conseqüência de um ato criador. Lei e regra não se impõem de fora e a priori, constrangendo ou limitando um ser que "poderia" se subtrair a elas. Ao contrário, emergem com esse ser, fazem parte de seu modus vivendi e, ao invés de o determinarem por limitação ou constrangimento, o determinam na medida em que constituem para ele um poder/fazer: território onde desenvolve suas capacidades. Por isso mesmo, autonomia significa antes de tudo autocriação, autopoiese: diferença entre aquilo que é construído por outro e aquilo que se constrói a si mesmo.

Mas o deslocamento da noção de lei ou determinação para a noção de criação só pode ajudarnos a pensar a autonomia como primeira na medida em que ela possa ser pensada fora da dicotomia entre criador e criatura, posto que tal dicotomia nos faria recair na heteronomia. A criação, além do mais, terá que ser pensada sem recurso a qualquer fundamento, sem recurso a qualquer realidade substancial desde sempre dada ou a qualquer forma que a priori viesse delimitar sua possibilidade ${ }^{3}$. Isso não implica, no entanto, que o processo criativo seja monolítico, unitário... Ao contrário, como veremos, ele não exclui a distinção de planos que se entrecruzam e se criam mutuamente, quer dizer, há um pouco de criatura no criador e um pouco de criador na criatura. Resta estabelecer qual o sentido que se deve atribuir a cada um, isto é, em que sentido o criador é criatura e em que sentido a criatura é criadora. Entrelaçar estes dois planos é pensar o ato de criação como inaugural, primeiro por relação a qualquer domínio de realidade criada, seja ele subjetivo ou objetivo. No entanto, devemos evitar tomar esta criação primordial como um Fiat Lux ou uma criação ex nihilo, e entendê-la como criação em um ato sempre concreto, atual. A instância criadora, portanto, sem ser externa ou transcendente ao que por ela é criado, deve ser pensada como um modo de operar que singulariza o vivo. O que esta nova teoria do vivo nos faz ver é que em toda criatura há uma dimensão autopoiética que a

É interessante notar que uma versão do problema formulado por Varela se dá na forma da interseção da biologia com a filosofia oriental, mais especificamente com o Zen Budismo. O que interessará Varela, inicialmente, é a maneira como esta filosofia busca um conhecimento sem fundamento (Varela, Thompson \& Rosch, 1993). abre para a criação. A um só tempo criatura e criador, organismo e auto-organização, os dois planos — o da criação e o do criador - se entrelaçam formando um circuito, no qual se diferenciam sem, contudo, poderem se separar.

Parece-nos que a dificuldade em pensar a autonomia reside justamente na tentação sempre renovada de separar e opor radicalmente planos que, embora distintos, não podem ser concebidos um sem o outro e são inseparáveis. Por aí, Varela nos faz desviar do senso comum, utilizado muitas vezes pela ciência e pela filosofia para definir a noção de diferença. Tal desvio do senso comum deve ser, neste contexto, entendido como recusa do pressuposto de que todo distinto é separável. Trata-se de uma atitude intelectual que rebate (e reduz) a realidade sobre o plano descontínuo e homogêneo do espaço, lá onde as coisas se distinguem como unidades discretas e isoláveis. Embora encontremos, nas noções de autonomia e autopoiese, uma maneira de superar esta atitude, na obra de Varela aparece com outro sentido e outro destaque a noção de senso comum. Aqui este termo designa o campo da experiência onde o conhecimento se dá como um "saber-fazer", um engajamento prático ou ativo no mundo, podendo-se verificar nele a "inscrição corporal do espírito" (Varela e cols., 1993). O senso comum ganha, portanto, este outro sentido, como o campo de uma ação que se desdobra no tempo e que, conseqüentemente, não pode ser completamente apreendida como uma realidade espacial delimitável. Sentido produzido no tempo e contextualmente, ele é o plano ontológico de onde emergem por determinação recíproca o sujeito e o objeto do conhecimento . Como afirma Varela: "a cognição não pode ser adequadamente compreendida sem o senso comum, que é nossa história física e social, ele nos faz deduzir que aquele que conhece e esse que é conhecido, o sujeito e o objeto, são a especificação recíproca e simultânea um do outro. Em termos filosóficos: o saber é ontológico" (Varela, 1980/1989b, p. 99).

Não obstante, tradicionalmente, o senso comum toma a diferença a partir da idéia de separação e mútua exclusão. E assim, acaba-se por constituir seja uma ontologia dualista (Descartes - coisa extensa / coisa pensante), seja uma teoria do conhecimento que só se exprime através da dualidade (Kant - sujeito transcendental / sujeito empírico). Mas, a quem acredita que a passagem do dualismo substancial para a dualidade subjetiva introduz algo de essencialmente novo, nós retrucamos que a forma de pensar a diferença permanece aí a mesma. Varela insiste no ponto seguinte: a autonomia (autopoiese) se assenta 
em uma operação de circularidade (reflexividade), onde dois planos distintos (organização e estrutura, lingüístico e extralingüístico, organismo e meio, planos de significação diferentes etc.) se determinam reciprocamente ao se criarem mutuamente.

A grande novidade deste pensamento - que é, ao mesmo tempo, sua grande dificuldade - reside nas tentativas de designação e nas estratégias de definição desta operação que, em resumo, é nada mais do que um incessante diferenciar-se. Trata-se, então, de opor às perspectivas duais um outro modo de articular a diferença. É o aprofundamento da noção de circularidade que vai nos permitir avançar na compreensão deste problema.

Varela nos fala dos "círculos criativos", numa tentativa de dar conta da experiência de autonomia como decorrência de uma operação peculiar, que se denomina comumente como círculos viciosos (Varela, 1981/1994) ${ }^{4}$. Na esfera da lógica, esta operação circular é expressa pela figura do paradoxo, que se constitui, para a tradição, como um limiar do pensável. O paradoxo, de fato, fere o "postulado segundo o qual as afirmações sobre algo não devem ser elemento constituinte desse algo". O que é pressuposto neste postulado é a separabilidade radical do plano da existência (objeto) relativamente ao plano da linguagem (sujeito). Assim, fora do paradoxo, a distinção entre os planos implica em sua separação. $\mathrm{O}$ importante no paradoxo é que, nele, o que "deveria permanecer separado se entrecruza (...) de maneira que dois planos confundem-se em um só e, no entanto, continuam diferenciáveis" (Varela, 1981/1994, p. 306).

Varela toma indistintamente como exemplos de paradoxo o koan de Quine ("Esta frase é falsa se incorpora aspas a si mesma") e o enunciado de Epimênides, o cretense ("Todos os cretenses são mentirosos"). Ambos, de fato, se constroem como círculos viciosos, possuindo, no entanto, consistências diferentes. O interessante no enunciado de Epimênides é o fato de ele extrapolar o domínio puramente lingüístico, designando uma operação de circularidade que conta com a exterioridade absoluta criada por que ela mesma. Pois dizer que todos os cretenses são mentirosos, em sendo um cretense, implica em fazer da circularidade o modo de desestabilização de um domínio de existência. De fato, neste paradoxo, o campo da enunciação em choque com o campo da referência produz a instabilidade, seja do enunciado

4 O conteúdo deste artigo foi retomado pelo autor na edição revisada para a língua francesa do seu livro Principles of Biological Autonomy. em sua pretensão à verdade, seja do mundo a que ele se refere. Enquanto no koan quiniano o círculo fecha o enunciado sobre ele mesmo, uma vez que o enunciado é o seu próprio referente, em Epimênides, o enunciado paradoxal faz parte do seu referente (já que é um ato cretense) porém não se confunde com todo o domínio do referente (o mundo cretense que se impõe como o exterior do enunciado). É esta exterioridade pressuposta pelo enunciado que acaba por sofrer também os efeitos vertiginosos da circularidade instaurada.

Imaginemos a situação em que Epimênides proferisse seu enunciado em uma assembléia cretense. Diferente do efeito produzido caso dissesse "Vocês todos são mentirosos", excluindo-se a si mesmo do domínio recoberto pelo enunciado, no caso do paradoxo as condições de verdade e falsidade não estão preestabelecidas nem conseguem se estabelecer, já que, em sendo verdadeiro, o enunciado se torna falso e, em sendo falso, torna-se verdadeiro. No entanto, este enunciado supõe um domínio que ele possa vir a recobrir, domínio que deve ser criado ao mesmo tempo que é suposto. Que cidade grega é esta cujos cidadãos são todos mentirosos, inclusive aquele que atesta tal verdade? Tal pergunta acerca do referente do enunciado de Epimênides faz com que a busca desta região recoberta pelo enunciado entre em um movimento circular e vertiginoso; pois se há esta Creta onde todos são mentirosos, logo, aquele enunciado, em sendo verdadeiro, é compelido a se confrontar com a sua inevitável falsidade, uma vez que é proferido por um cretense por definição mentiroso. E se, por outro lado, admitimos que o enunciado "Todos os cretenses são mentirosos" é falso, conseqüentemente, esta Creta dos que mentem não existe e Epimênides pode ser um cretense que diz uma verdade. E neste círculo incessante vamos passando do verdadeiro ao falso, enquanto aquilo que se diz faz parte daquilo sobre o que se fala. A Creta dita no enunciado se distingue sem se separar da Creta de que se fala; e, por esta inseparabilidade das duas Cretas distintas, a cidade de Epimênides se desestabiliza, nunca podendo ser uma mesma e tranqüila Creta. Logo, podemos concluir que, para a sustentação desse jogo circular, Creta é suposta como algo puramente indeterminado que funciona como um horizonte de nonsense para o sentido que o paradoxo enuncia.

Suportar tal paradoxo faz com que, necessariamente, $o$ enunciado passe a não poder mais se garantir em uma realidade preexistente que lhe sirva de referência. Sem referente, este enunciado só pode criar "dinamicamente" seu domínio que, por outro 
lado, passa também imediatamente a constituí-lo. Essa lógica do paradoxo foi reconhecida por Varela como idêntica à dinâmica da vida. Se, então, a vida é pensada como o paradoxo, a criação do vivo, assim como de seu mundo próprio (Umwelt) se faz pela circularidade, supondo sempre este horizonte puramente indeterminado como um plano de nonsense, a partir do qual emergem heterogêneas regiões de sentido (eu/mundo, enunciado/domínio, organismo/meio, lingüístico/extralingüístico .... $)^{5}$.

Notemos que essa circularidade do paradoxo, circuito paradoxal da vida, ao supor ou pressupor um tal plano de nonsense, se coloca perante uma exterioridade que não pode ser considerada nem objetiva nem subjetiva. Difícil seria pensá-la por referência à dimensão do espaço, como ademais, costuma-se pensar qualquer exterioridade. Quem sabe, então, se lançarmos mão da dimensão do tempo, as coisas se esclareçam mais facilmente? Um pensamento bergsoniano pode vir em nosso auxílio: $o$ real é ao mesmo tempo atual e virtual. Sabe-se, a partir dos comentários de Deleuze (1966), que Bergson propõe uma distinção do tempo diferente daquela normalmente empregada. Ao lado de passado, presente e futuro, dimensões temporais definíveis ao mesmo tempo dos pontos de vista subjetivo e objetivo (seja como vivido do sujeito, seja como objeto de relações no interior da vida social e da ciência), nosso filósofo distingue as dimensões do atual e do virtual no tempo. Trata-se de dimensões totalmente assimétricas e heterogêneas, pois que o atual é apreensível tanto do ponto de vista do sujeito como do ponto de vista do objeto, enquanto o virtual só é apreensível de um ponto de vista sui generis, a partir do qual se penetraria a experiência antes que esta fosse forçada a portar em si a distinção do subjetivo e do objetivo ${ }^{6}$. Ora, é interessante observar que esta distinção do atual e do virtual força Bergson a pensar o tempo a partir de uma operação singular de cisão onde as partes, melhor dizendo, os processos obtidos (atual e virtual), ao invés de se separarem, se torcem

Acerca da substituição da oposição self / nonself por este outro self / nonsense ver o artigo de Ana Maria C. de Faria (1987), assim como Nelson Vaz e Ana Maria C. de Faria (1990).

6 O tema da contraposição entre a experiência útil — onde se encara a experiência como tributária da distinção sujeito/objeto - e a experiência imediata — onde se tenta acessar a experiência em sua fonte, quer dizer, antes desse "tournant decisivo" a partir do qual ela sofre uma inflexão que a faz seguir o sentido de nossa utilidade e torna-se propriamente a experiência humana (Bergson, 1985/1896, pp. 204-206) um em direção ao outro, se refletem e entram em circuito.

Nossa existência atual, à medida que se desenrola no tempo, duplica-se assim de uma existência virtual, de uma imagem em espelho. Portanto, todo momento de nossa vida oferece dois aspectos: é atual e virtual, percepção de um lado, lembrança de outro. Cinde-se ao mesmo tempo em que se põe. Ou melhor, consiste nessa cisão mesma, pois o instante presente, sempre em movimento, limite fugidio entre o passado imediato que não é mais e o futuro imediato que não é ainda, reduzir-se-ia a uma simples abstração se não fosse precisamente o espelho móvel que reflete sem cessar a percepção em lembrança. (Bergson,1919/1985, p. 136) ${ }^{7}$.

Essa operação do tempo é uma operação de alteração: distinguindo-se e refletindo-se incessantemente, atual e virtual, no lugar de se separarem e formarem dois, alteram a natureza do circuito que os une: o que caracteriza esse circuito é sua multiplicidade, e não sua unidade. Por isso dir-seá que nesse mar de alteração, neste horizonte de nonsense, aparecem diferenciações múltiplas. Assim, esta cisão/alteração do tempo em duas dimensões distintas e inseparáveis dá necessariamente origem a uma cisão/diferenciação ou bifurcação.

$\mathrm{O}$ atual se caracterizaria como aquilo que é dado, determinado, se não fosse por sua inseparabilidade do virtual, que justamente é definido como o que não é nem dado nem "dável", o que é indeterminado, de forma que a subsistência do virtual no seio do atual joga este último na dimensão do devir, do ato em vias de se fazer. $\mathrm{O}$ atual se torna tendência, e o modo de ser de uma tendência é o de desenvolver suas virtualidades até que sua forma atual não mais as comporte e ela seja forçada a se bifurcar, diferenciando-se em duas novas tendências divergentes e imprevisíveis, pois não podem ser deduzidas da exclusiva consideração da tendência de onde surgiram. É somente nesse momento que a circularidade vertiginosa em que entram as dimensões do atual e do virtual dá lugar à produção dos múltiplos tipos de realidades distintas, e mesmo assim sempre provisórias e metaestáveis, que nós denominamos de "eu" e "mundo", "sujeito" e "objeto", "enunciado" e "referente" etc. Mais ainda, cada par considerado encerra em si uma multiplicidade de formas diferentes: nós tentamos mostrar que o paradoxo de Quine difere

\footnotetext{
7 OBS: as traduções dos textos citados neste trabalho são de nossa responsabilidade.
} 
em natureza daquele de Epimênides, assim como Bergson também encontra acoplamentos sujeito/objeto que diferem em natureza (torpor, instinto, inteligência).

A partir desta redefinição da dinâmica criativa (autopoiética) da vida, torna-se necessário pensar o vivo (este organismo, aquele indivíduo ou um sistema perceptivo) como uma unidade cuja existência se define frente a um mundo que lhe é coetâneo e igualmente determinado na mesma operação poiética ${ }^{8}$. E para além deste par em "acoplamento", o resto se define não como nonself mas como nonsense. Não há uma realidade exterior preexistente que o organismo venha finalmente a conhecer ou com a qual venha a se acoplar, assim como não há um organismo dado que se ofereça como garantia para o conhecimento de mundos futuros. Conhecer é a forma como, por uma ação gerativa, emergem tanto o pólo subjetivo quanto o objetivo da relação cognoscente. E assim é a vida: ato puro de criação sem criador, indeterminado determinante.

A questão que se coloca agora é a da operação concreta da circularidade da vida ou do indeterminado determinante que define a vida como dinâmica autopoiética e explica a emergência do vivo como atualização concreta desta dinâmica. Nos estudos da cognição, a noção de rede oferece a possibilidade de uma definição operacional da dinâmica autopoiética. É o que se dá, no campo das ciências cognitivas, com o advento das teorias neoconexionistas, que permitem pensar sistemas auto-organizados que, em seu operar, geram suas próprias regras. Eis aí o círculo criativo em sua dinâmica, onde já não se separam criador e criatura, determinante e determinado.

É neste sentido que Maturana e Varela pensam a operação circular própria à vida se desdobrando em rede de conexões que ampliam o campo do sentido na extensão com que se amplia o campo da criação de si. Estes autores da biologia do conhecimento são, portanto, atores do neoconexionismo, sobretudo nos campos da neurobiologia e da imunobiologia. Chega-

8 Em um diálogo com a teoria da evolução, Maturana e Mpodoziz, buscam resgatar a noção de conduta e repensar o papel do meio como agente de uma seleção natural. A noção de nicho definida como "domínio de existência" aponta para a dupla criação organismo/meio:

"Na medida em que o meio inclui o nicho e o nicho não preexiste ao ser vivo, tampouco preexiste o meio ao ser vivo que o ocupa; ao contrário, surge com ele. O domínio de existência de um ser vivo corresponde substancialmente ao que Von Euxküll (1957) chama seu Umwelt, e um mesmo ser vivo pode realizar distintas identidades ao realizar distintos nichos". (Maturana \& Mpodoziz, 1992. p 14). se mesmo a falar em uma "segunda geração da rede", que superaria, conservando-os, os avanços alcançados pelo modelo conexionista de explicação da cognição como efeito emergente de um sistema em rede (Varela \& Coutinho, 1991, pp. 159-166). Esta noção de rede é fundamental para que possamos entender a noção de autonomia, pois para que se efetive a superação do modelo de comando é preciso que se feche operacionalmente o sistema. É este o sentido do conceito de "clausura operacional", que deve ser entendida como a operação de base de todo sistema autopoiétco. São, portanto, autônomos ou autopoiéticos os sistema regidos por uma endodeterminação, tal como Maturana e Varela explicitam com a definição do conceito de "determinismo estrutural"'.

É notável que essa biologia implique, segundo Varela, na superação do modelo da representação, e que de imediato se torne necessário propor, para o domínio do conhecimento, um novo modelo que supere, a um só tempo, realismo e idealismo. É preciso ficar alerta para o fato de que a afirmação da vida como círculo criativo não incorre numa nova forma de idealismo solipsista. Para evitar tal encruzilhada se tentou, na tradição recente do cognitivismo computacional, manter a perspectiva da cognição como sistema input/output, sistema operacionalmente aberto que recebe informação do meio, de forma que, na leitura de Varela, esta perspectiva seria ainda tributária de certo realismo latente. O equívoco do cognitivismo seria manter-se seja na perspectiva do objeto como fundamento do conhecimento (aqui lembramos de um realista stricto sensu como o de James Gibson), seja na perspectiva do sujeito (todo neokantismo do cognitivismo computacional ou da etologia de Konrad Lorenz [Varela, 1980/1989b, p. 105]), posto que ambas as posições pressupõem a preexistência tanto do sujeito quanto do mundo, e uma relação entre os dois só possível a partir do modelo da representação ${ }^{10}$. Se, por um lado, a dinâmica da

9 Para os conceitos de "clausura operacional" e de "determinismo estrutural", ver Maturana e Varela, (1980/1972). Ver também Varela (1983. p. 147-164) e Varela (1995).

10 As alternativas do modelo da representação são descritas por Bergson da maneira seguinte: "Ou o espírito se regra pelas coisas, ou as coisas se regram pelo espírito, ou é preciso supor entre as coisas e o espírito uma concordância misteriosa". (1956/1907, p. 207). Mas existiria ainda uma alternativa, fora do modelo da representação, que consistiria em propor uma gênese simultânea do sujeito e do objeto tanto no domínio do conhecimento como também no domínio da vida. Essa empreitada de Bergson nos parece coincidir com aquela a que se propõem Maturana e Varela. 
circularidade é pensada como operação fechada sobre si mesma, por outro lado, ela é concebida como estando aquém da relação sujeito/mundo ou organismo/meio, de forma que esta dinâmica não pode estar isolando o sujeito nele mesmo. Ao contrário do solipsismo, o dinamismo circular funda sujeito e mundo ao mesmo tempo que funda a relação dos dois, supondo em sua operação sempre a "referência" a um horizonte indeterminado (anterior ao sujeito e ao mundo) a partir do qual ela se dá como criação de realidades subjetiva e objetiva (tal como Epimênides e aquela Creta indeterminada, criados a cada enunciação do paradoxo). Essas realidades criadas se multiplicam sem jamais esgotar a dinâmica da criação. São muitos mundos (M), muitos organismos (O e muitos tipos de relação entre eles $(\mathrm{R})$ que emergem desse plano indeterminado. A vida em sua evolução criadora funciona como um plano virtual que está sempre impondo abertura às realidades criadas, tornando inesgotável o processo de mudança ou "deriva natural" dos seres vivos.

A noção de deriva natural, central na obra de Maturana e Varela, atesta o sentido forte dado à dimensão tempo. Contra pressupostos da teoria da evolução darwinista, os autores afirmam que a evolução do vivo se dá como um fenômeno de "múltiplas derivas naturais" entre organismo e meio, não havendo progresso ou otimização adaptativa nesta relação. O que evolui é o acoplamento estrutural entre duas séries em variação contínua, não podendo nenhuma delas desempenhar a função de juiz deste desenvolvimento. (Maturana \& Mpodoziz, 1992 e Maturana \& Varela, 1995). A vida, portanto, é um fluxo temporal ou uma deriva. Talplano indeterminado estaria sempre em excesso frente aos MOR. E com isto não se deve supor que no domínio das realidades atuais o virtual se expresse como figura do negativo, como a falta do indeterminado na determinação. $\mathrm{O}$ atual comporta o virtual pelo que tem de excesso e não pelo que nele é carência - carência pelo fato de ser menos do que o todo de que ele é parte. Eis novamente o paradoxo de uma parte em que vigora todo o virtual. Parte e todo são agora duas dimensões da vida que não podem ser isoladas, separadas. Sem separar o todo de suas partes, abole-se a figura do nada ou da falta. Não há mais onde alojar a falta, já que as realidades se dão em excesso. $\mathrm{Na}$ verdade, esse excesso funciona internamente a essas realidades, tornando-as abertas ao tempo, sempre em deriva.

Vemos aqui o ponto de intersecção entre a teoria da autonomia de Varela e a concepção bergsoniana da criação. O pensamento de Bergson, com efeito, pode nos ajudar a entender o paradoxo dessa dimensão de excesso que se incorpora nos MOR em processo de criação incessante, ao mesmo tempo em que a operação do círculo criativo tende a coincidir com o plano indeterminado.

A noção de criação, segundo o filósofo, só pode ser pensada no tempo, pois fora do tempo ela implica em ilusão. Com efeito, quando se pensa o ato criador fora do tempo, coloca-se em causa tudo o que existe, todo o real mais todo o possível, e, conseqüentemente, nós não podemos escapar à conclusão de que tudo é atual, de que "tudo está dado de uma vez por todas, e que é preciso postular, de toda eternidade, ou a multiplicidade material ela mesma, ou o ato criador desta multiplicidade, dado em bloco na essência divina" (Bergson, 1907/1956, p. 241). Do ponto de vista da criação não há coincidência entre real e atual; ou seja, é preciso supor que o real comporta uma dimensão de inatualidade, uma dimensão virtual não menos real que aquela do atual. Mais do que isso, é preciso supor também que a criação é o processo pelo qual uma virtualidade se desenvolve (se intensifica e muda) através de múltiplas e diferentes atualizações. Assim, o ato criador é necessariamente duplo, pois ele é próprio a alguma coisa que se cria, criando outras coisas. Isto não seria possível sem que o criador permanecesse "unido" e imanente à criatura, mesmo sendo diferente e tomando distância em relação a ela. Ora, esta espécie de imanência na diferença ou na distância é justamente a essência do círculo criativo, que conjugaria ao mesmo tempo duas operações: a "clausura operacional", que corresponderia à atualização de um MOR, e a "deriva natural", que corresponderia à subsistência da dimensão do virtual no seio da MOR criada (dito em outras palavras, corresponderia a uma abertura temporal da MOR). Nós poderíamos dizer que a criação se faz sempre em um Todo Aberto, seja ele orgânico, psíquico, social ...

O Todo é um sistema fechado pela própria natureza (fechamento espacial ou da estrutura), mas isto não significa que o Todo seja dado, pois sempre subsiste nele uma certa abertura paradoxal ao tempo, posto que é de sua essência estar incessantemente em estado de mutação e criar sempre algo de novo. $\mathrm{O}$ Todo é atravessado por alguma coisa que impede justamente que ele se esgote de uma só vez: ele é assombrado por virtualidades que o ultrapassam, que transbordam sua atualidade. Toda realidade natural é, então, dupla: por um lado, atual, por outro, virtual. O virtual deve ser concebido justamente como um excesso "preso" à forma atual, algo como uma exigência de criação que, ao se fazer sentir, "empurra" a forma para um novo devir. Por isso, de um certo ponto de vista, nós poderíamos dizer que o Todo é 
uma criatura (algo criado) e que o virtual, imanente a ele, é um excedente, um resto, surgido no momento da criação e que não se atualizou. Trata-se de uma diferença que, dentro da coisa, é alguma coisa que a ultrapassa.

Em termos bergsonianos a dimensão atual do Todo chama-se matéria, enquanto sua dimensão virtual chama-se élan vital. O élan vital exprime este excesso, essa diferença interna ao Todo. A criação envolve, então, uma certa relação do virtual com o atual, do élan vital com a matéria, e, a noção que exprime mais adequadamente esta relação é aquela de problema. Examinando-se essa noção torna-se possível fazer a passagem da esfera da criação do ser vivo para aquela da natureza do ato cognitivo que lhe concerne. Assim, o viver, o conhecer e o fazer passam a coincidir na operação do círculo criativo.

Mais uma vez, vemos se entrecruzar a teoria da autonomia de Varela com a concepção de criação de Bergson. $\mathrm{O}$ ato cognitivo, para Varela, é muito mais do que simplesmente resolução de problema. E esta posição contrasta com uma tendência dominante nos estudos cognitivistas, pois, tradicionalmente, o trabalho da inteligência, como de resto o que caracteriza qualquer ato cognitivo, é a solução de problemas. Entenda-se, aqui, por solução de problema a atividade de uma inteligência que se encontra frente a um conjunto de condições predefinidas. Nesta perspectiva tradicional, o que fica necessariamente fora do esquema explicativo é o caráter criativo ou inventivo da cognição; esta se definindo, portanto, como atividade recognitiva. Conhecer reduz-se assim à solução de um problema cujo êxito depende do reconhecimento de "elementos, propriedades e relações de regiões dadas previamente"(Varela, Thompson \& Rosch, 1993). Mas ao contrário, a biologia do conhecimento, com Maturana e Varela, assume a tarefa de pensar a cognição menos como atividade de solução do que de posição de problema. Verifica-se que, mais uma vez, o eixo de análise é deslocado, apostando-se no caráter inventivo da cognição, sobretudo se entendemos, como o faz Bergson, que colocar um problema implica sempre em criação.

Mas a verdade é que se trata, em filosofia e mesmo alhures, de encontrar o problema e conseqüentemente de colocá-lo, mais do que de resolvê-lo (...) Colocar o problema não é simplesmente descobrir, é inventar. A descoberta concerne ao que já existe, atualmente ou virtualmente; ela certamente viria cedo ou tarde. A invenção dá ser ao que não era, ela teria podido não vir jamais (...)
Posição e solução de problema estão próximos aqui de ser equivalentes: os verdadeiros grandes problemas só são colocados quando são resolvidos." (Bergson, 1922/1986, p. 51-52).

Bergson considera então, que a noção de problema é muito mais importante para pensar a evolução vital do que a determinação negativa da necessidade. Um problema nunca é o efeito de uma necessidade que exige ser satisfeita, mas, ao contrário, são necessidades novas que surgem da solução de um problema. Todo problema tem necessariamente uma dupla origem: por um lado, há uma exigência de criação, uma diferença que se cria ou um excesso que quer passar; por outro lado, um obstáculo a superar, uma resistência ao movimento ou uma condição com a qual se deve contar. O problema está sempre na relação de uma superabundância com a coisa na qual essa superabundância se criou; ele marca a inadequação da coisa àquilo que está em excesso nela, exprime uma espécie de tensão entre o ser e o devir do ser. Em outras palavras, um problema só se cria através de uma mudança que se exprime por uma desproporção entre aquilo que se é e aquilo que se está em via de se tornar. Assim, um problema verdadeiro cria mais do que simplesmente um novo modo de pensar: ele cria um novo modo de existir, uma nova forma de subjetividade.

É neste movimento de criação problemática de modos de existência que deve ser entendida a vida em seu caráter cognitivo. Conhecer é a criação de si do vivo na ação do vivo. Eis novamente o sentido circular e a dificuldade da fórmula proposta por Maturana e Varela da qual partimos: a relação de imanência entre viver, fazer e conhecer. Como uma serpente que morde o próprio rabo, ou como as imagens paradoxais de Escher ${ }^{11}$, vemos que todo ato de conhecer produz um mundo no qual aquele que conhece se constitui. Neste círculo criativo, é abolida toda existência previamente garantida, restando, portanto, o ato puro da criação com o qual a vida (e não o vivo) se identifica. Nessa ação infinitiva de fazer emergir mundos, a cognição ganha este estatuto ontológico de ato de decretação de existências — uma "enação" como prefere Varela, utilizando-se de um neologismo derivado do vocabulário jurídico: to enact designando

11 São freqüentes, nos textos de Maturana e Varela, as referências aos trabalhos do gravador neerlandês M. C. Escher. Em especial os autores utilizam, como ilustração, a gravura "Mãos que desenham", na qual duas mãos se desenham reciprocamente. Acerca da relação entre os autores e Escher (Passos, 1995, p.41-50. 
o ato de decretar uma realidade. E, por "enação", não se deve entender a ação de alguém sobre algo ou a distância entre a lei decretada e aquilo sobre o que ela legisla. Este ato, para ser expressão da autonomia do vivo, deve ser entendido como ação criadora na qual se distinguem sem se separar a criatura e o criador. A vida é, então, o que excede no vivo, o que nele se dá como abertura temporal para a criação. A vida é autopoiese, seguindo um curso ou deriva natural que deixa atrás de si territórios existenciais constituídos e tem à frente existências virtuais.

\section{REFERENCIAS}

Bergson, H. (1956) L'evolution créatrice. Paris: PUF. (Originalmente publicado em 1907)

Bergson, H. (1985) Matière et mémoire. Paris: PUF. (Originalmente publicado em 1896)

Bergson, H. (1985) L'énergie spirituelle. Paris: PUF. (Originalmente publicado em 1919)

Bergson, H. (1986) La pensée et le mouvant. Paris: PUF. (Originalmente publicado em 1922)

Deleuze, G. (1966) Le bergsonisme. Paris: PUF.

Deleuze, G. (1988) Diferença e repetição. Rio de Janeiro: Graal. (Originalmente publicado em 1968)

Faria, A. M. C. de (1987) Corpos estranhos, a imunologia entre Freud e Darwin. Ciência e Cultura, 39 (7), 625-630.

Kastrup, V. (1995) Autopoiese e Subjetividade: sobre o uso da noção de autopoiese por G. Deleuze e F. Guattari. Revista do Departamento de Psicologia da UFF, 7, 86-96.

Maturana, H. \& Mpodoziz, J. (1992) Origen de las especies por medio de la deriva natural. Santiago, Publicação Ocasional, 16 do Museu de História Natural do Chile.
Maturana, H. E \&Varela, F. (1980) Autopoiesis and cognition: the realization of the living. Dordrecht: D. Reidel Publishing Company. (Originalmente publicado em 1972)

Maturana, H. E \&Varela, F. (1995) A árvore do conhecimento. Campinas: Editorial Psy. (Originalmente publicado em 1987)

Passos, E. (1995) Um paradigma estético nos estudos da cognição. Pesquisa e Música, 1, 41-50.

Varela, F. (1989a) Autonomie et connaissance: essai sur le vivant. Paris: Seuil, (Tradução Ampliada do Original em inglês de 1980).

Varela, F. (1989b) Connaître: les sciences cognitives, tendences et perspectives. Paris, Seuil.

Varela, F. (1994) O círculo criativo: esboço histórico-natural da reflexividade. Em P. Watzlawick, A realidade inventada. (pp. 302-316) Campinas: Editorial Psy II.. (Originalmente publicado em 1981)

Varela, F. (1983) L'auto-organization: de l'apparence au mécanisme. Em P. Dumouchel \& J. D. C. de Cerisy. (Org.). L' auterganization: de la physique au politique. Paris, Seuil.

Varela, F. \& Coutinho, A. (1991) Second generation immune networks. Immunology Today, 12, (5), 159-166.

Varela, F., Thompson, E. \& Rosch, E. (1993) L' incription corporelle de l' esprit: sciences cognitives et expérience humaine. Paris: Seuil.

Vaz, N. \& Faria, A. M. C. (julho,1990) The construction of immunological identity. Ciência e Cultura, 42 (7), 430-440.

Recebido em 04/09/2003

Aceito em 11/03/2004

Endereço para correspondência: André do Eirado, Rua Dr. Arthur Tibau, 5 / 1303, CEP: 24.210-160, Ingá, Niterói - RJ.

E-mail eirado@terra.com.br 